\title{
INVESTIGASI NUMERIK KEKUATAN STRUKTUR CHECK VALVE 1/2" 9K Psi MENGGUNAKAN FINITE ELEMENT SOFTWARE
}

\author{
Budi Setiyana* dan A Johan Kurniawan \\ Departemen Teknik Mesin Fakultas Teknik Universitas Diponegoro \\ Jl. Prof. Sudharto, SH Kampus Tembalang, Semarang \\ *Email: bsetiyana@yahoo.com
}

\begin{abstract}
Abstrak
Check Valve adalah sebuah alat yang digunakan untuk mengatur cairan hanya mengalir ke satu arah saja dan mencegah aliran ke arah sebaliknya (backflow). Check valve tidak menggunakan tuas untuk mengatur aliran (membuka dan menutup), tapi menggunakan pegas dan tekanan dari aliran itu sendiri. Karena fungsinya yang dapat mencegah aliran balik (backflow), check valve sering digunakan sebagai pengaman dalam sistem perpipaan baik untuk fluida cair maupun gas. Karena fungsinya yang sangat penting, komponen check valve sering menjadi bagian kritis dalam sistem perpipaan. Berkaitan dengan bentuk strukturnya yang sulit dianalisis secara teoritik, analisis kekuatan check valve harus dilakukan secara numerik dengan software Metoda Elemen Hingga. Tulisan ini menganalisis kekuatan komponen check valve diameter 0.5 inchi dengan tekanan internal 9000 psi dengan menggunakan software aplikasi berbasis Metoda Elemen Hingga berupa ANSYS. Hasil analisis menunjukkan bahwa struktur chek valve cukup cukup kuat baik dari sisi deformasi, tegangan maupun faktor keamanannya.
\end{abstract}

Kata kunci: ANSYS, backflo, Check Valve.

\section{PENDAHULUAN}

Valve atau katup adalah sebuah perangkat yang terpasang pada sistem perpipaan, yang berfungsi untuk mengatur, mengontrol dan mengarahkan laju aliran fluida dengan cara membuka, menutup atau menutup sebagian aliran fluida. Katup/valve memiliki peran penting dalam suatu industri seperti industri migas yang meliputi pengaliran kedalam kolom destilasi.

Check valve adalah alat yang digunakan untuk membuat aliran fluida hanya mengalir ke satu arah saja atau agar tidak terjadi reversed flow/back flow untuk mengalirkan fluida hanya ke satu arah dan mencegah aliran ke arah sebaliknya yang tidak menggunakan handel untuk mengatur aliran, tapi menggunakan system pegas dan tekanan dari aliran fluida itu sendiri. Karena fungsinya yang dapat mencegah aliran balik (backflow) check valve sering digunakan sebagai pengaman dari sebuah equipment dalam sistem perpipaan baik untuk fluida cair maupun gas. Kegagalan fungsi dari katup ini akan mengganggu proses produksi yang berkaitan dengan aliran fluida, bahkan bisa menimbulkan kecelakaan kerja. Sehingga dalam system perpipaan, check valve termasuk komponen perpipaan yang kritis. Aplikasi valve jenis ini banyak dijumpai pada outlet/discharge dari centrifugal pump dan compressor.
Cara kerja atau mekanisme aliran pada check valve diberikan pada gambar 1 dengan diberikan tiga buah gambar. Ketika laju aliran fluida sesuai dengan arahnya, yaitu ke arah kiri (gambar yang atas), laju aliran tersebut akan membuat plug atau disk terbuka karena pegas katup akan meregang akibat dorongan aliran fluida seperti yang terlihat pada gambar tengah. Sebaliknya jika ada tekanan balik yang datang dari arah berlawanan (ke arah kanan), maka plug atau disk tersebut akan menutup lubang sehingga tidak ada aliran balik, seperti terlihat digambar paling bawah.
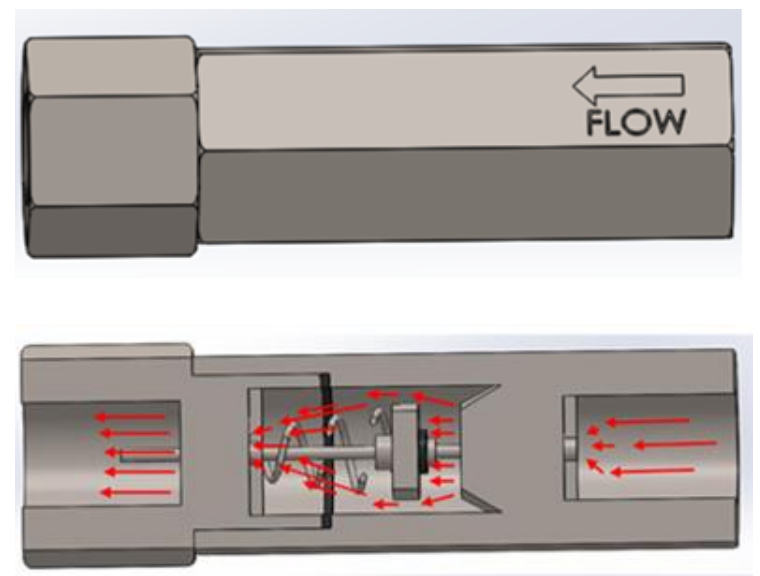


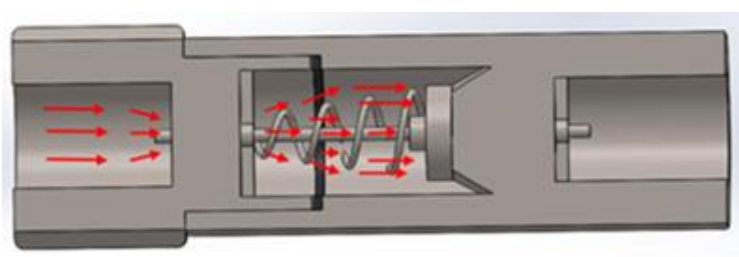

Gambar 1. Mekanisme kerja pada Check Valve saat menerima aliran fluida

Mekanisme retak/patahan pada check valve adalah hal yang sangat berbahaya. Dalam memperkirakan kerusakan pada level tekanan tertentu, awal kerusakan yang berupa kerusakan yang kritis terlihat dari perubahan karakteristik material dan komponen check valve. Umumnya ekplorasi yang lengkap dari mekanisme retak/patahan komponen check valve pada praktiknya dideteksi dengan pengujian atau test tanpa merusak (Non Desdructive Test/ NDT).

Dengan menggunakan analisis numerik dengan software Metoda Elemen Hingga, maka akan diketahui kemampuan struktur check valve dalam menahan beban yang diterima. Setelah didapati peta hasil dalam analisis, tahapan akhir adalah menarik kesimpulan dari analisis yang telah dilakukan, yang akan menjawab persoalan dari kasus ini, apakah keretakan yang terjadi pada komponen check valve itu karena lemahnya kekuatan struktur valve tersebut.

Dengan mengacu pada latar belakang di atas tulisan ini menganalisis kekuatan struktur pada Check Valve dengan diameter 1/2" untuk tekanan kerja 9000 Psi yang biasa dipakai dalam system perpipaan. Valve ini sering dinyatakan dalam bentuk Check Valve 0.5" 9K. Analisis dilakukan dengan menggunakan software ANSYS. Topik ini diambil berdasarkan data di katalog ataupun kasus di lapangan yang mana valve tipe ini sangat banyak digunakan.

\section{METODE PENELITIAN}

Metode atau prosedur yang dilakukan dalam penelitian ini diberikan pada Gambar 2 . Mulai dari identifikasi penggunaan check valve di literatur maupun di lapangan, jenis material valve, pemodelan yang dipilih, analisis hingga observasi hasil analisis. Analisis dikatakan berhasil jika proses simulasi numerik bersifat konvergen dan memberikan hasil yang wajar dan logis.

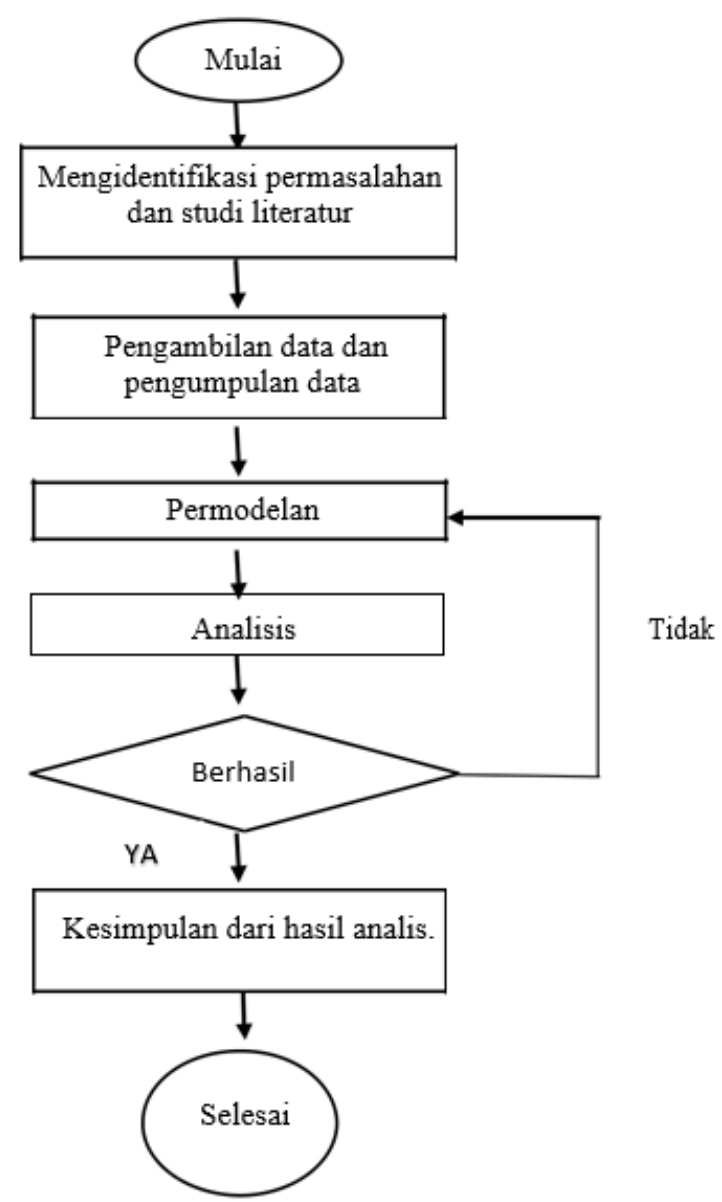

Gambar 2. Diagram alir penelitian

Low Alloy Steel atau Baja AISI 4130 merupakan baja paduan rendah yang mengandung kromium dan molybdenum. Material ini merupakan bahan baku utama untuk struktur check valve. Baja ini memiliki sifat ulet atau daktil serta mempunyai faktor temperatur yang tinggi sehingga banyak digunakan dalam industri. Ini memiliki kandungan karbon rendah, dan karenanya dapat dilas dengan mudah. Sifat mekanik material ini dapat dilihat pada Tabel 1.

Tabel 1. Sifat mekanik Alloy Steel AISI 4130

\begin{tabular}{ll}
\hline Alloy Steel AISI 4130 & \\
\hline Yield Strength & 75.000 Psi \\
Ultimate Tensile Strength & 106.023 Psi \\
Modulus of Elasticity & 30.000 .000 Psi \\
Density & $7.850 \mathrm{~kg} / \mathrm{m} 3$ \\
\hline
\end{tabular}

Pembuatan gambar untuk Check Valve menggunakan SOLIDWORKS yang biasa digunakan untuk merancang part permesinan atau susunan part permesinan yang berupa assembling dengan tampilan 3D. Gambar atau 
model dari check valve diberikan pada gambar 3.

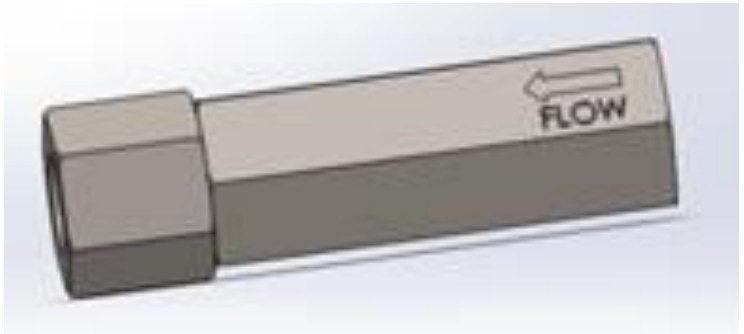

\section{Gambar 3. Pemodelan Check Valve}

Analisis kekuatan struktur check valve menggunakan software ANSYS yang merupakan software berbasis finite element analysis (FEA). Untuk analisis disini, digunakan versi ANSYS 18.1. Adapun simulasi numerik menggunakan ANSYS untuk check valve ini diberikan pada Gambar 4, yaitu ketika struktur dilakukan proses diskritisasi dan meshing.

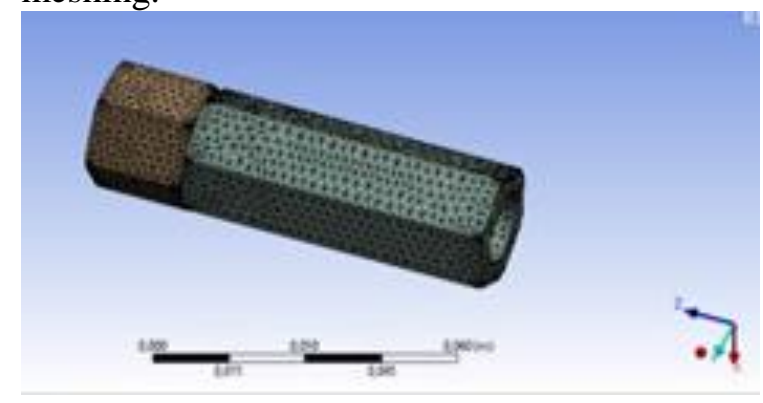

Gambar 4. Meshing struktur check valve

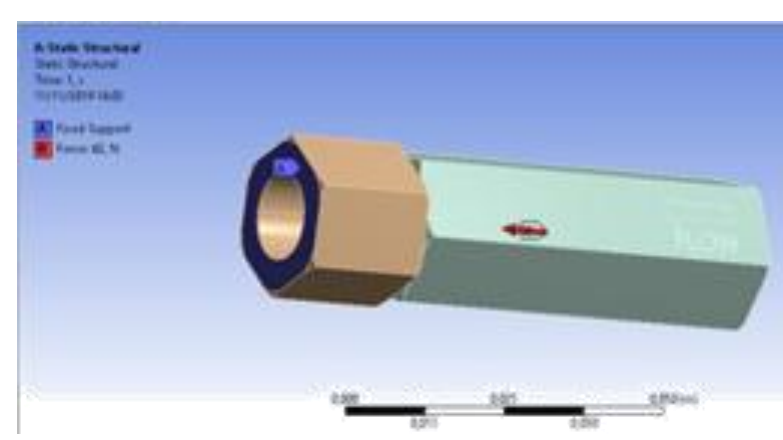

\section{Gambar 5. Parameter pembebanan}

Perlakuan pembebanan diasumsikan ketika Check valve mendapatkan internal pressure sebesar 9000 Psi seperti pada gambar 5. Bagian ujung kiri sebagai tumpuan atau referensi, dan ekivalen mendapat gaya $620 \mathrm{~N}$ arah sumbu valve yaitu arah sumbu $\mathrm{z}$.

\section{HASIL DAN PEMBAHASAN}

Hasil yang didapat dari analisis adalah deformasi struktur, tegangan von Mises dan angka keamanan dari masing-masing bagian dari struktur. Deformasi berkaitan dengan tingkat regangan sedangkan tegangan berkaitan dengan ketahanan terhadap gagal patah atau retak.

Gambar 6 menunjukkan besar deformasi struktur, baik bagian dalam valve maupun bagian luarnya. Dari hasil simulasi dapat dilihat jika deformation yang terjadi pada Check Valve yang ditunjukan dengan warna yang berbeda beda. Warna biru atau ungu menunjukkan deformasi yang rendah dan warna merah atau orange menunjukkan deformasi yang besar. Pada internal check valve terlihat ada beberapa bagian yang menunjukan warna merah atau terdeformasi maksimum. Sedangkan pada body check valve terlihat deformasinya angka maksimal nya pada angka $9 \times 10^{-8} \mathrm{~mm}$. Perlu dicatat bahwa deformasi diukur dari poisis tumpuan.

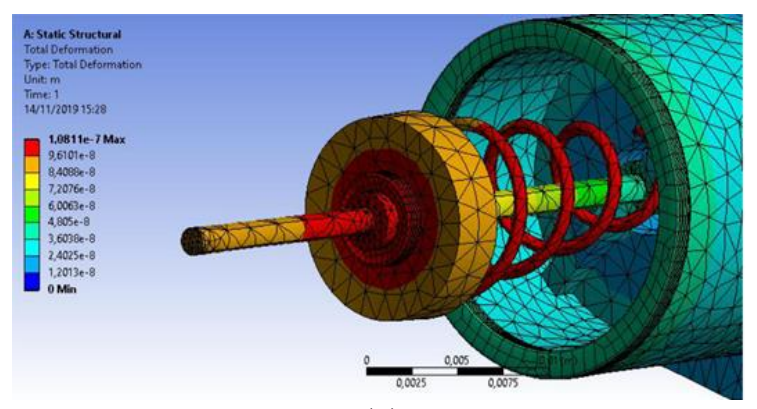

(a)

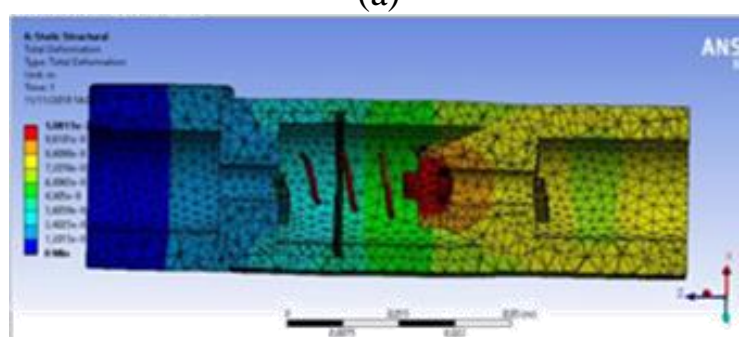

(b)

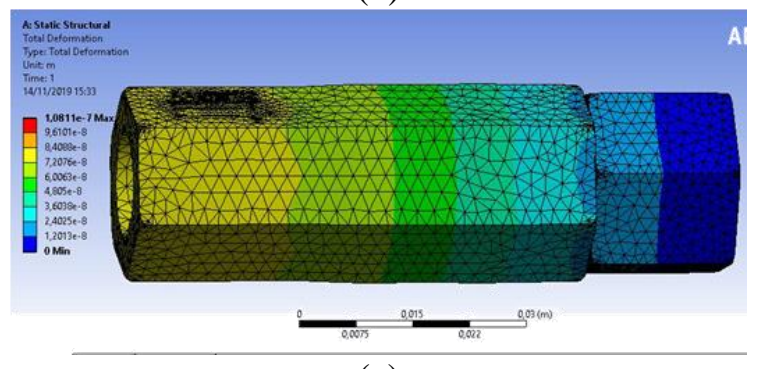

(c)

Gambar 6. Deformasi (a) komponen dalam (b) bagian dinding dalam dan (c) dinding luar 
Tegangan yang terjadi pada struktur valve diberikan pada gambar 7. Gambar (a) menampilkan distribusi tegangan bagian dalam valve, sedang gambar (b) menunjukkan tegangan bagian luar valve. Secara umum terlihat bahwa distribusi tegangan relatif merata. Hal ini menunjukkan bahwa dimensi struktur sudah cukup bagus untuk menerima beban berupa tekanan dari fluida didalamnya. Tegangan yang terjadi pada Check Valve dapat dilihat berwarna biru muda dan ditunjukan pada angka $1,1 \times 10^{6} \mathrm{~Pa}$. Teori tegangan yang dipakai adalah tegangan von Mises yang umum dipakai untuk logam baja yang elastis.

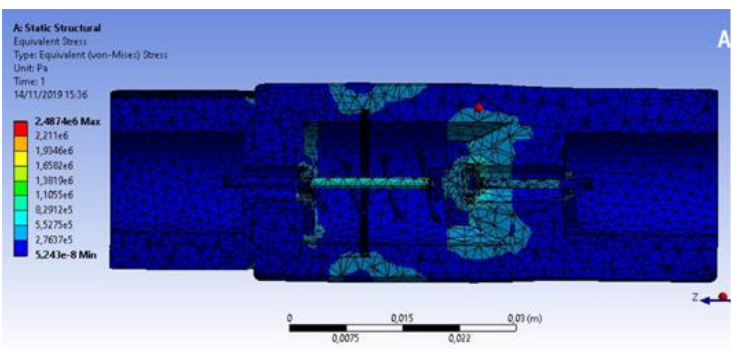

(a)

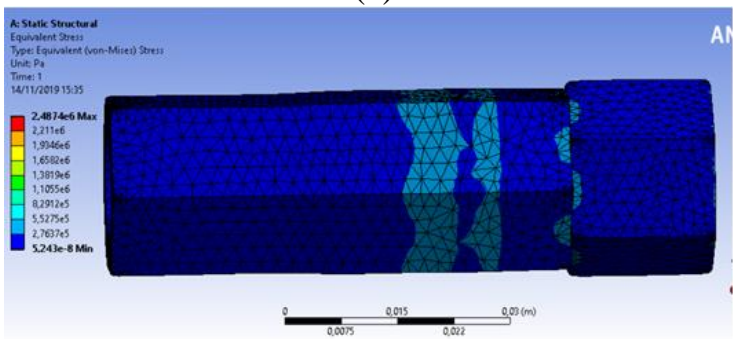

(b)

Gambar 7. Von Mises Stress (a) bagian dalam dan (b) bagian luar valve

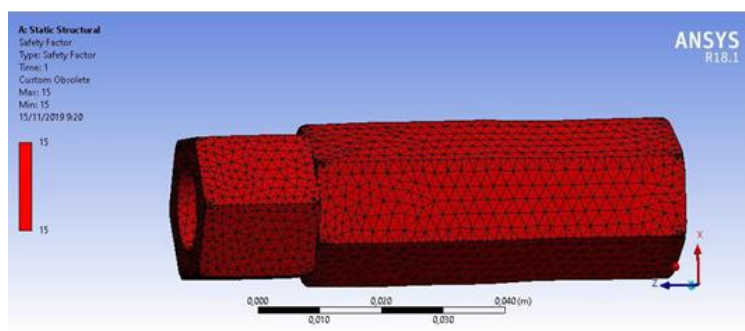

Gambar 8. Safety Factor

Pada simulasi ANSYS, Safety Factor dapat dilihat pada gambar 8 yaitu sebesar 15 , yang menjelaskan bahwa desain check valve ini masih aman untuk digunakan karena syarat dari safety factor yaitu diatas 1. Dari sini terlihat bahwa hasil analisis kekuatan struktur memberikan hasil yang sangat aman, sehingga keretakan material yang terjadi mungkin karena adanya kecacatan material, keausan akibat lamanya pemakaian atau efek kimiawi akibat fluida yang mengalir.

Dari hasil analisis diatas didapat bahwa deformasi maksimal yang diterima oleh body Check Valve adalah sebesar $9 \times 10^{-8} \mathrm{~mm}$ dan mempunyai nilai yang lebih tinggi jika dibandingkan dengan penelitian lain yang membahas tentang analisis gate valve ataupun ball valve. Adapun von Mises Stress yang terjadi pada Check Valve dapat dilihat berwarna biru muda dan ditunjukan pada angka $1,1 \times 10^{6}$ $\mathrm{Pa}$ dan juga lebih tinggi dibandingkan dengan gate valve dan ball valve. Pada analisis Safety Factor atau factor keamanan, di dapatkan pada angka 15 yang berarti sangat aman dan desain check valve ini layak untuk di pakai dari sisi kekuatan struktur.

\section{PENUTUP}

Kesimpulan dari analisis kekuatan struktur pada check valve $1 / 2$ " $9 \mathrm{~K}$ adalah sebagai berikut:

1. Deformasi maksimal yang diterima oleh body Check Valve adalah sebesar $9 \mathrm{x}$ $10^{-8} \mathrm{~mm}$.

2. Tegangan berupa von Mises Stres yang terjadi pada Check Valve dapat dilihat berwarna biru muda dan ditunjukan pada angka $1,1 \times 10^{6} \mathrm{~Pa}$.

3. Pada Analisis Safety Factor di dapatkan pada angka 15 yang berarti masih aman dan desain check valve ini layak untuk di pakai dari sisi kekatan struktur.

\section{DAFTAR PUSTAKA}

Segerlind, Larry J., 1984, Applied Finite Element Analysis, edisi Kedua, Canada: John Wiley and Sons Inc.

Smallman, Raymond E. and R.L. Bishop, 1999, Modern physical metallurgy and materials engineering, ButterworthHeinemann.

Timoshenko, S., 1980, Strength of Material, Edisi Kedua. New York: D. Van Nostrad Company Inc.

Rizky Arman, Yovial Mahyoedin, Kaidir, Nando Desilpa, 2019, Studi aliran air pada Ball Valve menggunakan metoda simulasi Computational Fluid Dynamics, Jurnal Kajian Teknik Mesin Vol.4 No. 1; P-ISSN: 2502-843X E - ISSN 240369671.

Bisma Herlambang, Tri Mulyanto, 2020, Analisis Kekuatan Gate Valve 2 9/16 3000 psi akibat tekanan fluida menggunakan Finite Element Analysis 
SOLIDWORKS 2018, Journal of Mechanical Engineering and Mechatronics ISSN: 2527-6212, Vol. 5 No. 1, pp. 21-27, Pres Univ Press Publication, Indonesia.

Meri Rahmi, Delffika Canra, Suliono, 2018, Analisis Kekuatan Ball Valve akibat tekanan fluida menggunakan Finite Element Analysis, Jurnal Teknologi Terapan | Volume 4, Nomor 2, p-ISSN 2477-3506 e-ISSN 2549-1938.

G. Rethwisch, D., \& Callister, W. D., 2007, Material Science and Engineering: An Introduction (8 ed.). New York: John willey \& sons.

Design and Selection of Check Valves Val-Matic Valve \& Mfg. Corp. • www.valmatic.com valves@valmatic.com• 630-941-7600 Copyright (C) 2018 Val-Matic Valve \& Mfg. Corp. 